\title{
Construction of aminated MIL-53(Al) functionalized carbon nanotube for efficient removal of Bisphenol AF and Metribuzin
}

\author{
Xueping Quan*, Zhongqiao Sun*, Junli Xu, Siyang Liu, Yide Han, Yan Xu, Hao \\ Meng*, Junbiao $\mathrm{Wu}$, and Xia Zhang*
}

Faculty of Chemistry, Northeastern University, Liaoning, 110819, P R China.

\section{Chemicals and Measurement Methods}

The chemicals could be applied directly, and deionized water of $18 \mathrm{M} \Omega \mathrm{cm}^{-1}$ was used. The morphology observation was conducted on Hitachi SU-8010 type SEM and JEM-2100F model TEM. The HRTEM was recorded with a Tecnai G2F30 FEI microscope. The powder X-ray diffraction (PXRD) was collected from a X-rays diffractometer with $\mathrm{CuK \alpha}$ in $5 \%$ min of scanning rate (PANalytical Empyrean, Netherlands). X-rays photoelectron spectra (XPS) were conducted on ESCALAB 250 (Xi) apparatus equipped $\mathrm{Al} \mathrm{K} \alpha$ radiation in $500 \mu \mathrm{m} \mathrm{X}$-ray spot. Raman spectrum was measured using a XPLORA instrument with a laser source of $532 \mathrm{~nm}$. Fourier transformation infrared (FT-IR) were recorded on Bruker VERTEX70 model Infrared spectrophotometer. $\mathrm{N}_{2}$ sorption curves were collected by ASAP2020M type Micromeritics analyzer at $77 \mathrm{~K}$. The concentration of organics was measured with Cary $60 \mathrm{UV}-\mathrm{V}$ is spectrophotometer. 

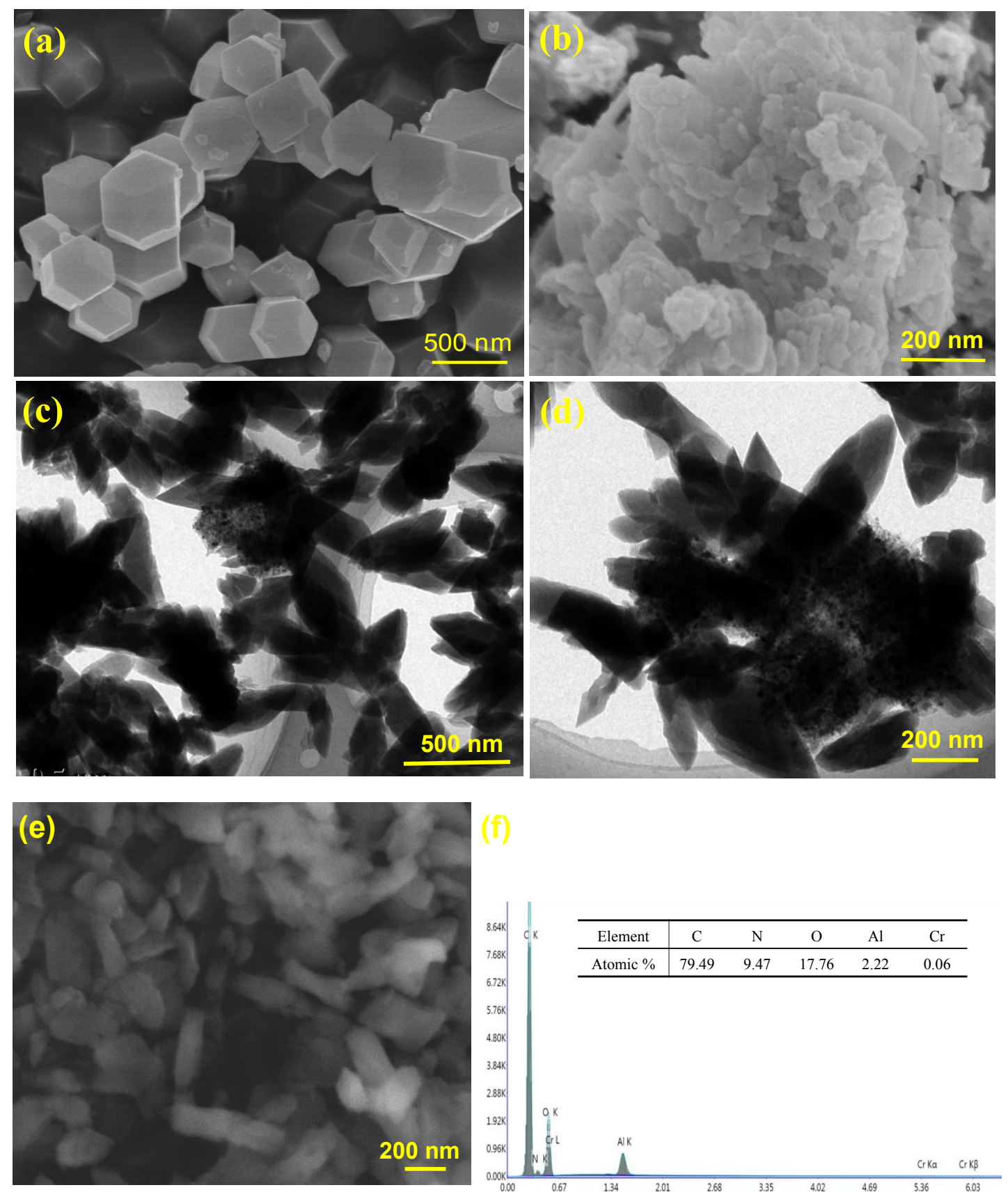

Figure S1 SEM images of pristine ZIF-67 (a) and aminated MIL-53(Al) (b) particles;

TEM images (c, d) of N-MIL@CNT under different magnification ; SEM image (e) of aminated MIL-53(Al)/PVP ; EDS profile(f) of N-MIL@CNT . 


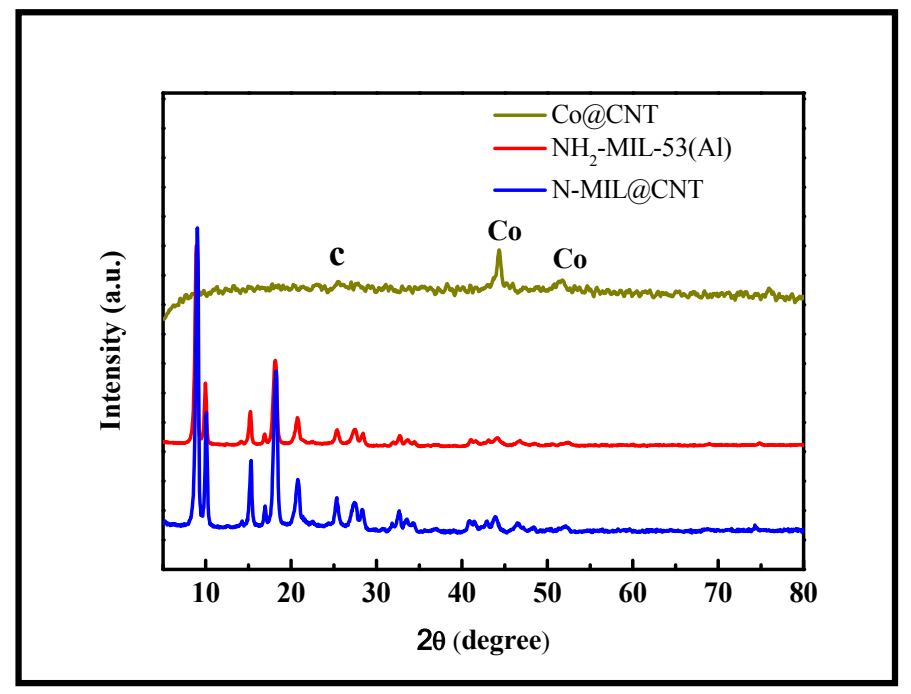

Figure S2 XRD patterns of Co@CNT, aminated MIL-53(Al) and N-MIL@CNT.

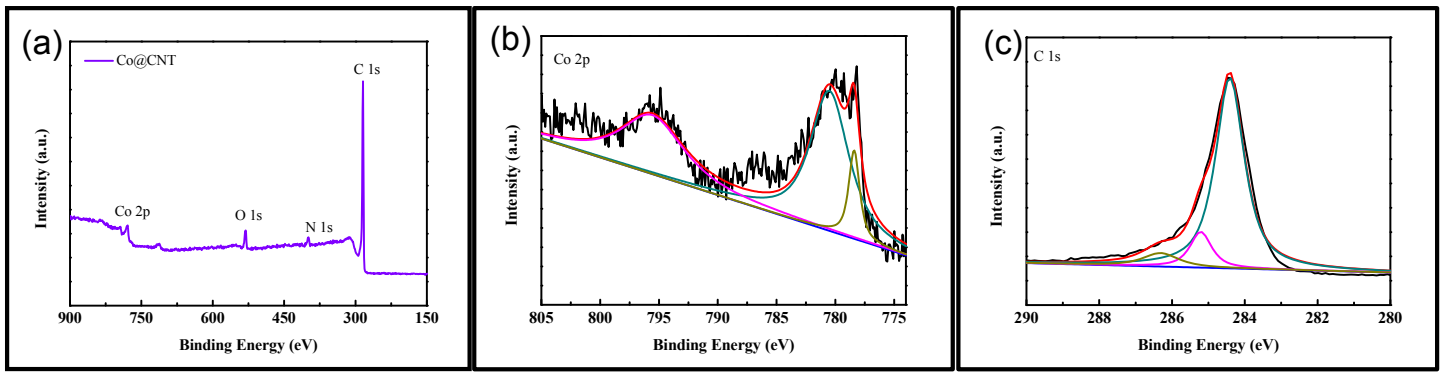

Figure S3 Broad XPS pattern (a), and high-resolution Co 2p XPS spectra (b) and C1s

(c) for $\mathrm{Co} @ \mathrm{CNT}$.

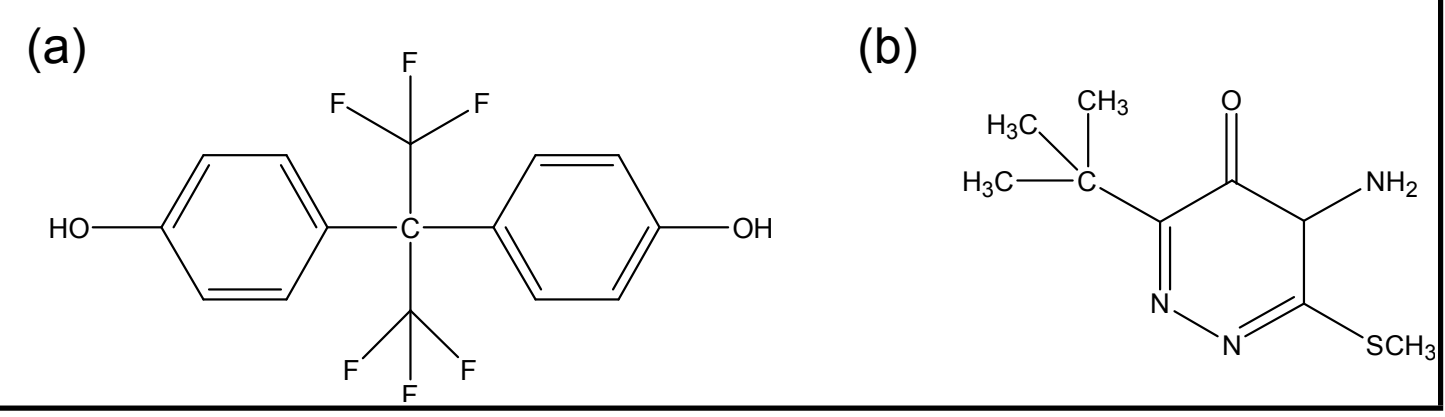

Figure S4 The molecular structure of BPAF (a) and Metribuzin (b). 


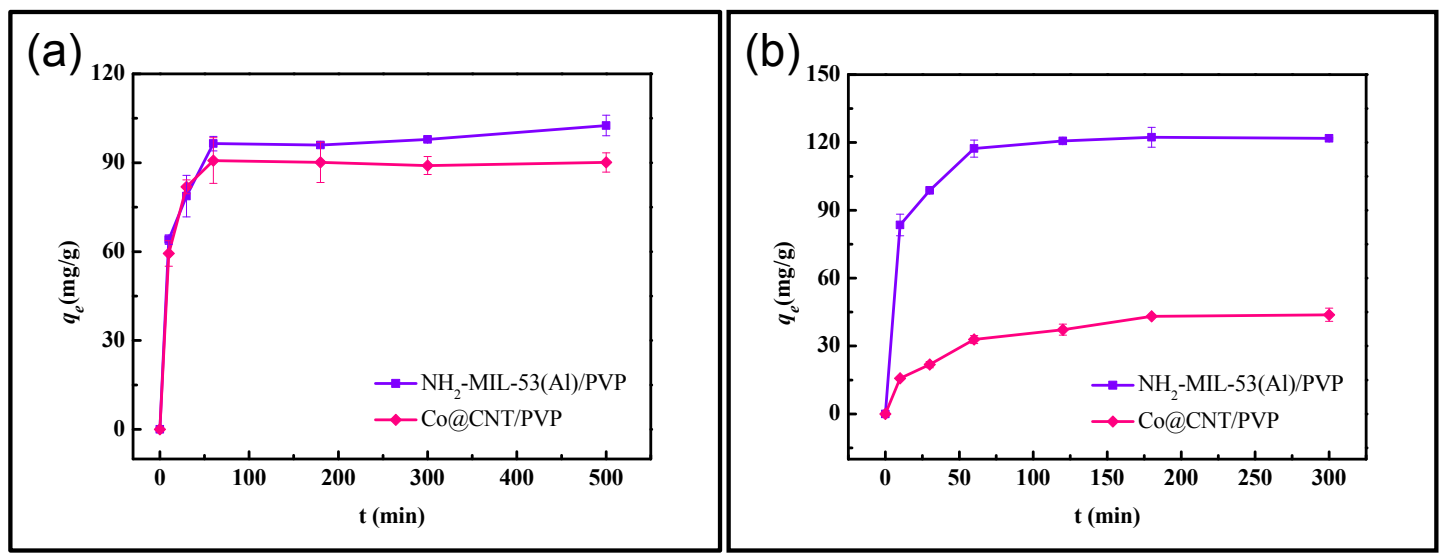

Figure S5 Adsorption kinetics of BPAF (a) and Metribuzin (b) by aminated MIL-53(Al)/PVP and Co@CNT/PVP.

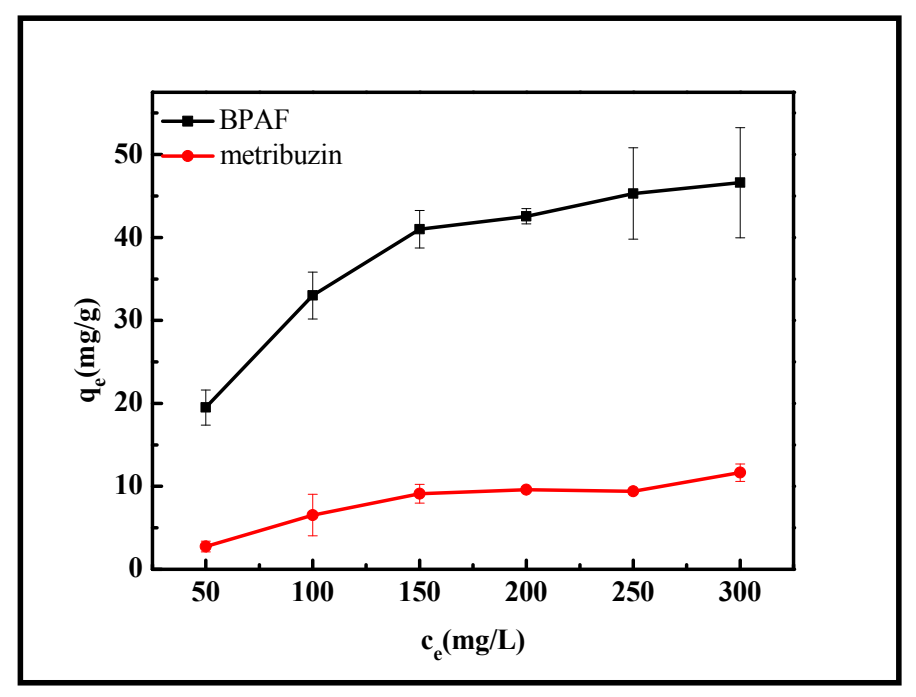

Figure S6 Adsorption isotherm of the two organics on ZIF-67 particles. 


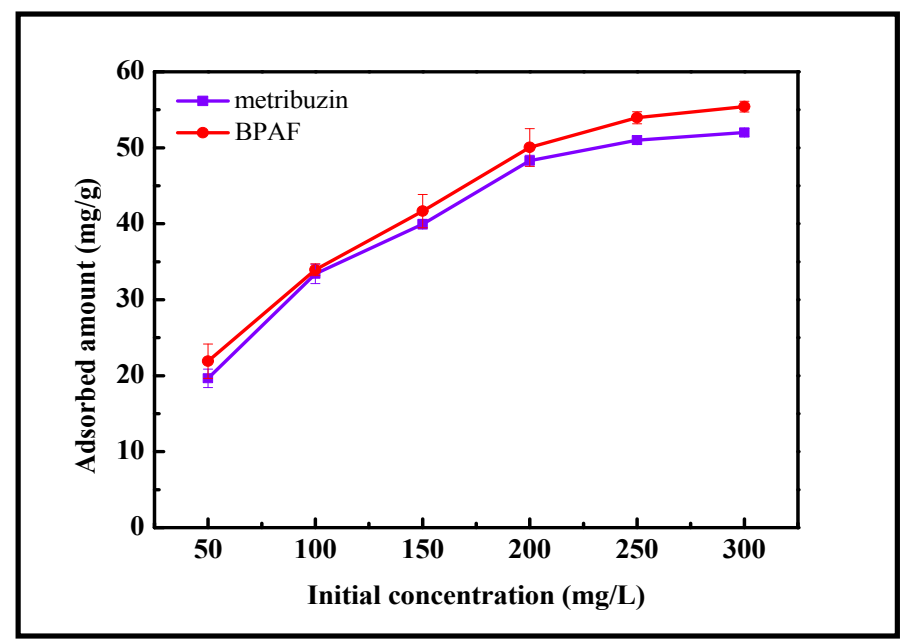

Figure S7 Adsorption isotherm of the two organics by the mechanical mixtures of pure CNT and aminatd MIL-53(Al) with mass ratio of 30mg/300mg.

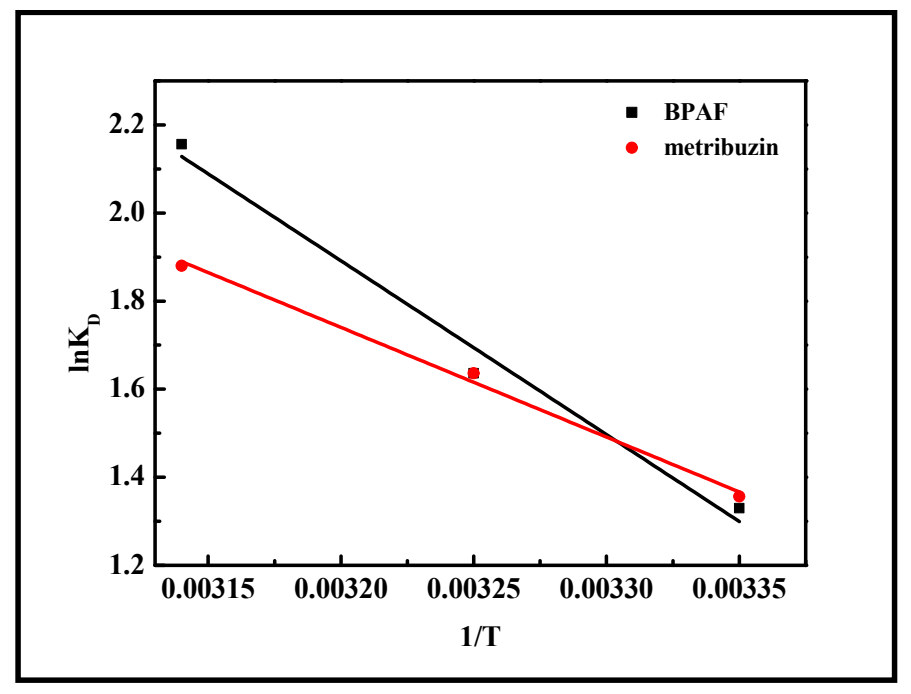

Figure S8 Plotting curves of $\ln K_{D}$ versus $1 / T$ for the adsorption of BPAF and Metribuzin on N-MIL@CNT. 


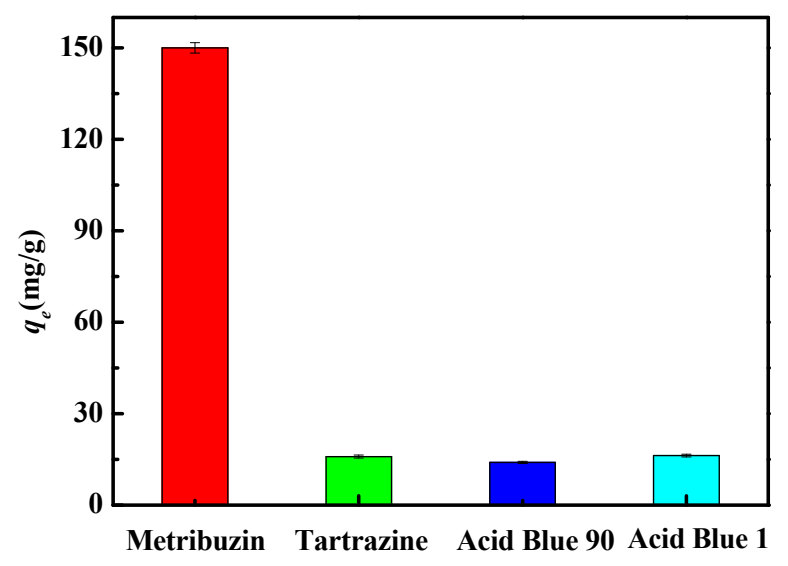

Figure S9 Comparison of adsorption capacity of Metribuzin and other dyes by N-MIL@CNT.

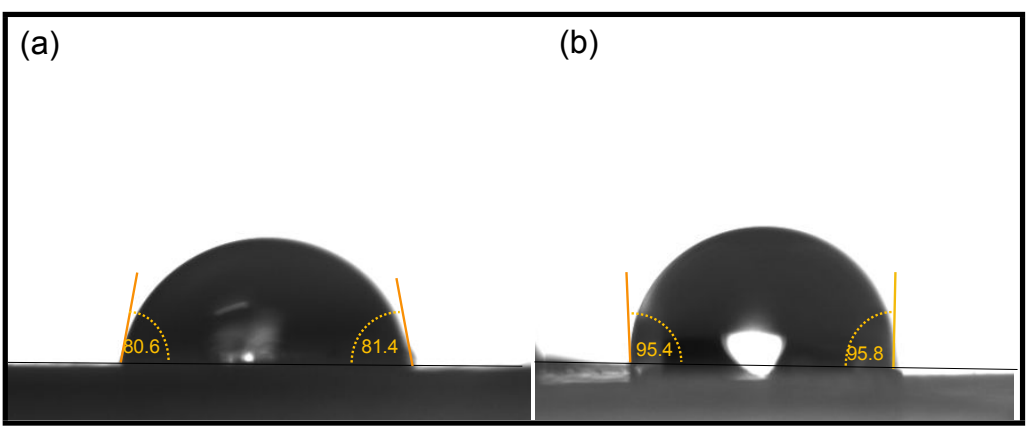

Figure S10 Comparison of the contact angle between pure PVDF (a) and N-MIL@CNT (b). 


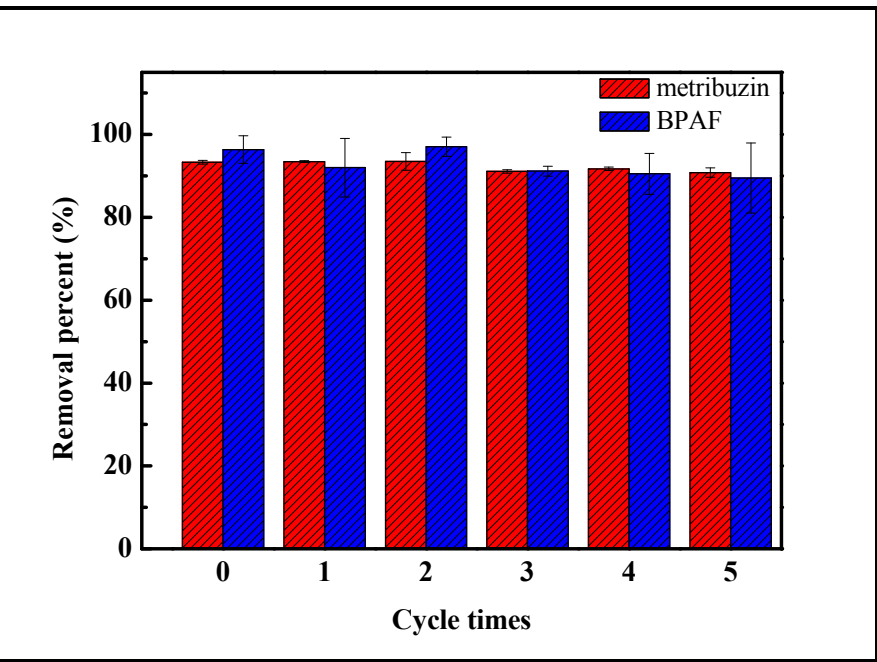

Figure S11 Reusability of N-MIL@CNT in the cyclic removal of BPAF and Metribuzin.

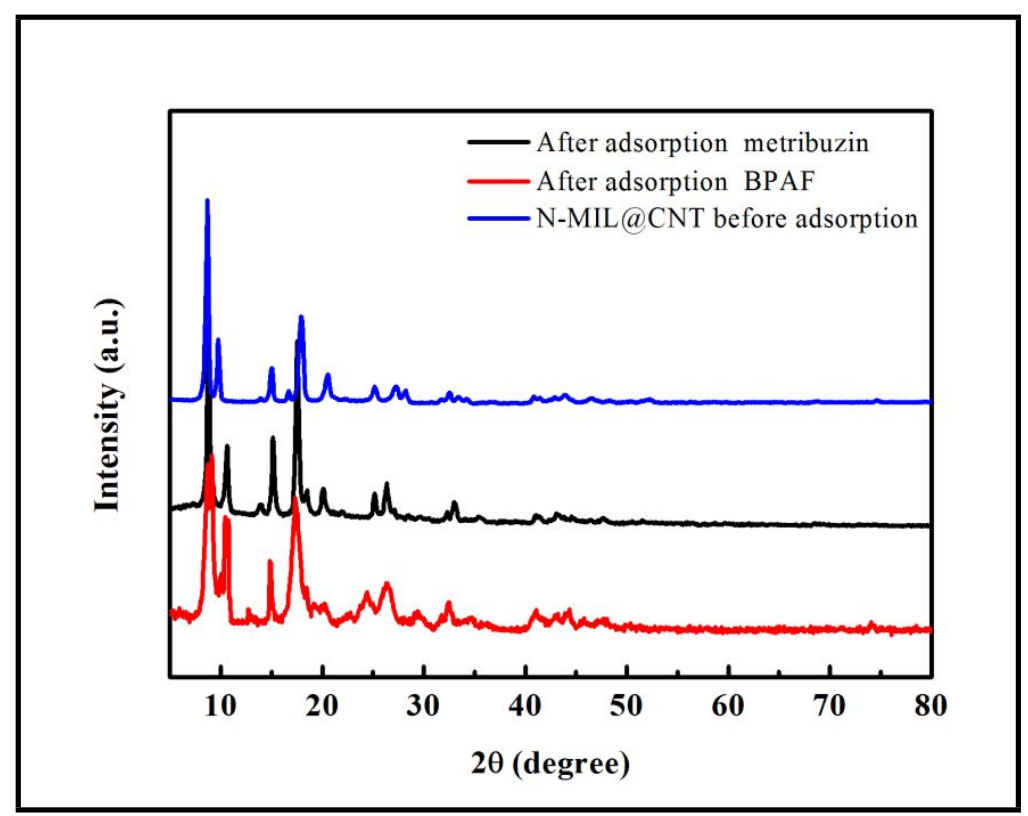

Figure S12 XRD patterns of N-MIL@CNT before and after the adsorption of BPAF and Metribuzin. 
Table S1 The calculated parameters by using pseudo-first-order kinetics, pseudo-second-order and intra-particle kinetic models for the adsorption of two organics on N-MIL@CNT

\begin{tabular}{|c|c|c|c|c|c|c|c|c|c|}
\hline \multirow[b]{2}{*}{$\begin{array}{l}\text { Orga } \\
\text { nics }\end{array}$} & \multirow[b]{2}{*}{$T$} & \multicolumn{3}{|c|}{ Pseudo-first-order kinetics } & \multicolumn{3}{|c|}{ Pseudo-second-order kinetics } & \multicolumn{2}{|c|}{$\begin{array}{l}\text { intra-particle } \\
\text { model }\end{array}$} \\
\hline & & $k_{l}\left(\min ^{-1}\right)$ & $\begin{array}{c}q_{e} \\
(\mathrm{mg} / \mathrm{g})\end{array}$ & $R^{2}$ & $\begin{array}{c}k_{2} \\
(\mathrm{~g} / \mathrm{mg} / \mathrm{min})\end{array}$ & $\begin{array}{c}q_{e} \\
(\mathrm{mg} / \mathrm{g})\end{array}$ & $R^{2}$ & $\begin{array}{c}k_{d} \\
(\mathrm{mg} / \mathrm{g} \\
\left./ \mathrm{min}^{0.5}\right)\end{array}$ & $R^{2}$ \\
\hline \multirow{3}{*}{$\begin{array}{c}\text { BPA } \\
\text { F }\end{array}$} & 298 & $1.1 \times 10^{-2}$ & 126.5 & $\begin{array}{c}0.97 \\
4\end{array}$ & $2.111 \times 10^{-4}$ & 234.7 & 0.999 & 5.91 & $\begin{array}{c}0.84 \\
3\end{array}$ \\
\hline & 308 & $8.37 \times 10^{-3}$ & 93.7 & $\begin{array}{c}0.93 \\
6\end{array}$ & $2.88 \times 10^{-4}$ & 250 & 0.999 & 5.29 & $\begin{array}{c}0.78 \\
7\end{array}$ \\
\hline & 318 & $1.95 \times 10^{-2}$ & 100.1 & $\begin{array}{c}0.98 \\
2\end{array}$ & $3.05 \times 10^{-6}$ & 275.5 & 0.999 & 4.72 & $\begin{array}{c}0.82 \\
4\end{array}$ \\
\hline \multirow{3}{*}{$\begin{array}{l}\text { Metri } \\
\text { buzin }\end{array}$} & 298 & 0.0152 & 61.0 & $\begin{array}{c}0.88 \\
0\end{array}$ & $6.81 \times 10^{-4}$ & 173.9 & 0.999 & 3.36 & $\begin{array}{c}0.71 \\
7\end{array}$ \\
\hline & 308 & 0.0158 & 68.6 & $\begin{array}{c}0.95 \\
6\end{array}$ & $4.3 \times 10^{-4}$ & 190.8 & 0.999 & 4.10 & $\begin{array}{c}0.81 \\
8\end{array}$ \\
\hline & 318 & 0.0202 & 69.4 & $\begin{array}{c}0.90 \\
2\end{array}$ & $6.53 \times 10^{-4}$ & 199.2 & 0.999 & 3.18 & $\begin{array}{c}0.82 \\
2\end{array}$ \\
\hline
\end{tabular}

